\title{
Hands-on engineering courses in the COVID-19 pandemic: adapting medical device design for remote learning
}

\author{
Yanning Liu ${ }^{1} \cdot$ Aishwarya Vijay $^{2} \cdot$ Steven M. Tommasini ${ }^{1,3} \cdot$ Daniel Wiznia $^{3,4,5}$
}

Received: 1 September 2020 / Accepted: 18 December 2020 / Published online: 7 January 2021

(c) Australasian College of Physical Scientists and Engineers in Medicine 2021

\begin{abstract}
The COVID-19 pandemic has challenged the status quo of engineering education, especially in highly interactive, hands-on design classes. Here, we present an example of how we effectively adjusted an intensive hands-on, group project-based engineering course, Medical Device Design \& Innovation, to a remote learning curriculum. We first describe the modifications we made. Drawing from student pre and post feedback surveys and our observations, we conclude that our adaptations were overall successful. Our experience may guide educators who are transitioning their engineering design courses to remote learning.
\end{abstract}

Keywords COVID-19 $\cdot$ Engineering education $\cdot$ Remote learning $\cdot$ STEM $\cdot$ Product design $\cdot$ Medical device design

\section{Introduction}

The COVID-19 pandemic has challenged the status quo of engineering education, especially in highly interactive, hands-on design classes.[1,2] Traditionally, these classes are held in maker spaces and fabrication labs and therefore, can be profoundly impacted by the lack of an innovative design studio which facilitates communication and a collaborative campus environment.[3] Our intention with this article is to demonstrate that engineering design courses can be successfully held remotely. We provide an example of

\section{Supplementary information The online version of this article} (https://doi.org/10.1007/s13246-020-00967-z) contains

supplementary material, which is available to authorized users.

Daniel Wiznia

daniel.wiznia@yale.edu

1 Department of Biomedical Engineering, Yale University, New Haven, CT, USA

2 Department of Internal Medicine, Northwestern University, Chicago, IL, USA

3 Department of Orthopaedics and Rehabilitation, Yale University, New Haven, CT, USA

4 Department of Orthopaedics and Rehabilitation, Joint Reconstruction, Yale University, New Haven, CT, USA

5 Department of Mechanical Engineering \& Materials Science, School of Engineering \& Applied Science, Yale University, New Haven, CT, USA how we effectively adjusted an intensive hands-on, group project-based engineering course, Medical Device Design and Innovation.[4].

Medical Device Design and Innovation is a project focused course offered to all Yale University students cross listed within the Mechanical and Biomedical Engineering Departments. The course syllabus contains two successive group-based projects, an orthopedic implant hardware failure analysis and redesign project and a Medical Device Design Challenge project, in conjunction with lectures and field trips to the hospital and medical device company campuses. Amid the COVID-19 pandemic, the course transitioned to distance learning in the second half of the semester, from early-March to late-April (7 weeks) (Fig. 1). During the 2-week Spring Break, the faculty modified the second half of the semester to accommodate remote learning, including the Medical Device Design Challenge project, the remaining lectures and field trips. To evaluate the students' experiences, we conducted student feedback surveys for the course before and after the term.

Here, we first describe the class modifications that were made in response to remote learning. Then, we evaluate the teaching outcomes through students' achievements and survey feedback, after which we discuss the feasibility of transforming a design class to remote learning. 


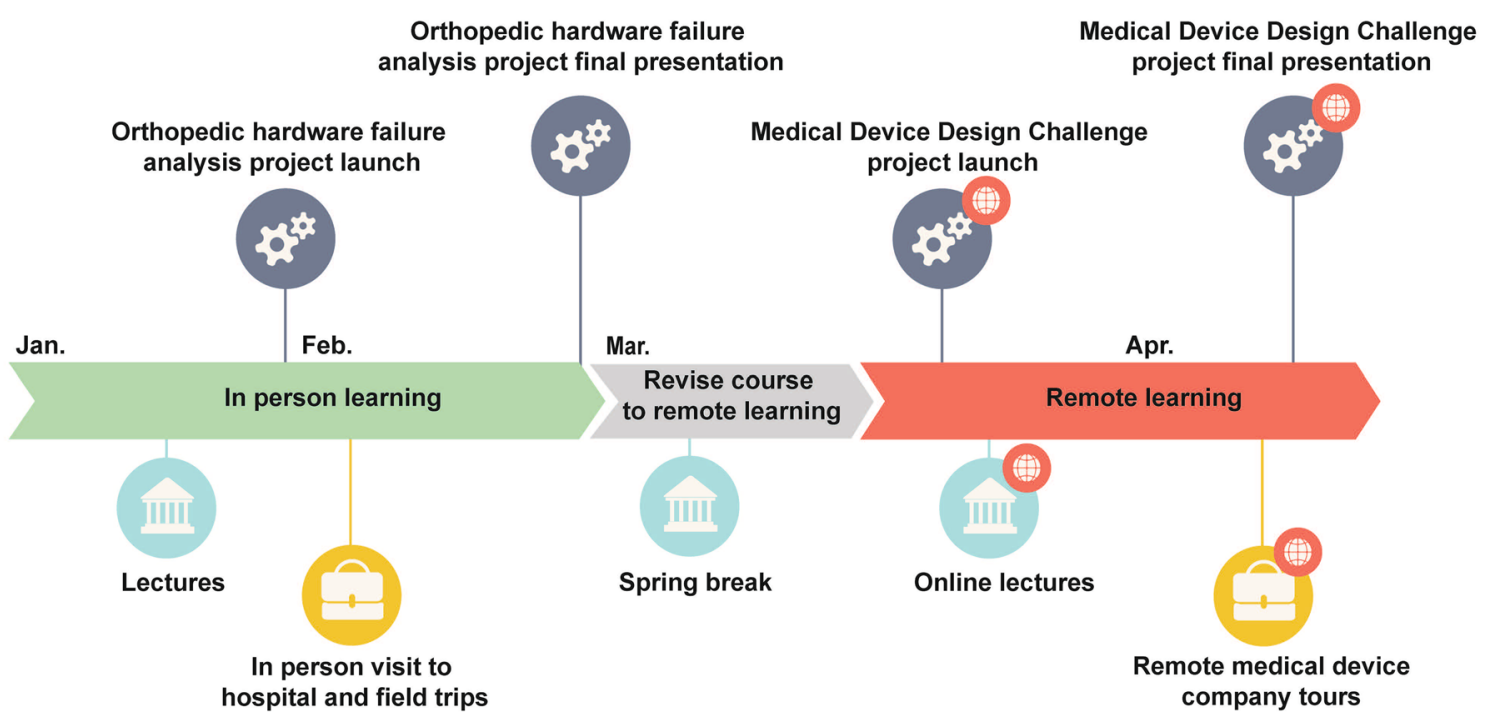

Fig. 1 The course Timeline of Medical Device Design and Innovation in Spring 2020. The course was transitioned to remote learning midMarch to late-April

\section{Materials and methods}

The following steps are the changes we made in response to remote learning.

\section{Lectures and field trips}

- All previously scheduled in-person lectures were delivered remotely through Zoom.

- In replacement of in-person field trips, medical device companies conducted virtual tours of their facilities, showcasing their design, manufacturing and validation processes.

\section{Medical device design challenge project}

The medical device design project was a group-based design project where each group (4-5 students) was matched with a clinical mentor who presented a real-world medical problem. Led by clinicians and medical device engineering professionals, the teams were expected to formulate ideas, iterate designs and eventually develop a product prototype. The project was completely remote and spanned 8 weeks from early-March to the end of the semester.

Knowing the challenges and constraints of completing the project remotely, the teaching faculty made the following adjustments:
- They required weekly team Zoom meetings with the project clinical mentors, course faculty and teaching fellows.

- They encouraged the groups to adapt from utilizing the maker space (the in-lab prototyping and testing) to alternative simulations using software.

- $\quad$ For example, students had increased remote access through our institution's Virtual Private Network to essential engineering software, including SOLIDWORKS (Dassault Systemes, Waltham, MA) for computer-aided design (CAD), Simpleware ScanIP (Synopsys, Mountain View, CA) for medical image segmentation and ABAQUS finite element analysis (FEA) (Dassault Systemes, Boston, MA).

- They increased the project budget for each group from $\$ 500$ to $\$ 1000$.

- The Yale Center for Engineering Innovation and Design (CEID) design fellows and machinist provided consultations regarding methods of fabricating and prototyping.

- In addition, the CEID provided remote 3D printing and machining services, and provided mail service to deliver the $3 \mathrm{D}$ printed/machined prototypes to the teams.

\section{Student surveys}

We conducted self-administered electronic surveys [5] before and after the class to evaluate the class outcome. The surveys are required by the University as a form of course quality improvement to allow the students to 
provide anonymized feedback. The results are utilized by the Mechanical Engineering and Biomedical Engineering Department Chairs to evaluate course quality and content. As these survey results were collected as a quality improvement initiative and not as a research study, ethics review board approval was not required. The pre- and post-class survey questions were planned and created prior to the launch of the class. The post-class survey was revised to address the online learning experience. The complete survey questions and results are provided in the supplemental material.

\section{Results}

44 students showed interest in the class and completed the pre-class questionnaire. 22 students registered and completed the course, of which 19 students $(86.3 \%)$ participated, and 16 students $(72.7 \%)$ completed the post-class survey.

\section{Connectivity and learning space}

$31 \%$ and $13 \%$ of students experienced internet connectivity problems and difficulties in finding a quiet study environment, respectively. Students in the Pacific time zone (31\%) found the start time (9 am Eastern Standard Time) challenging. Because the transition to remote learning occurred in the middle of the semester, class times were fixed, and schedules could not be altered. To account for this, classes were recorded, however, the interactions with the class and speakers were lost.

\section{Lectures and field trips}

$82 \%$ of the students who completed the post-class survey indicated they were satisfied with the remote lectures. Nonetheless, the students' feedback revealed that it is more challenging to build in-person interactions under the remote teaching format. The difficulties of communication and forming bonds were particularly manifest in the medical device company virtual tours, where $44 \%$ of the students said they did not have enough opportunities to meet and network with industry medical device engineers.

\section{Hands-on experience outcome}

\section{Learning how to use software}

Modern engineering designs rely on software simulations more than ever $[6,7]$. In the pre-class survey, $76.2 \%$ and $88.1 \%$ of the students indicated they expected to use finite element and CAD software in their future careers respectively. In contrast, merely $18.1 \%$ and $71.5 \%$ of the students were comfortable with the above two software before the class. To bridge the gap, the course emphasized software skill learning and application throughout the lectures and projects. Particularly, due to the lack of lab and maker space access during remote learning, CAD and software simulations became the primary alternative tools to in-lab prototyping and testing. Comparing the pre- and post-class surveys, more students became comfortable using the software for FEA, image segmentation and CAD (Fig. 2a). Moreover, they were more confident about applying these skills in their future careers (Fig. 2b).

\section{Medical device design project}

Despite the challenges of completing a hands-on group design project remotely, all 5 project teams successfully finished the ideation and iterative design stage of the project. The topics and detailed information of 5 group projects are summarized in Table 1 . Notably, among the 5 projects, 4 of them were hardware design oriented, which were heavily reliant on lab and maker space access. With the guidance of the mentors and course instructors, all the groups were able to overcome the limitations in remote learning through software simulations and remote services provided by the CEID. As an example, the Proximal Humerus Fracture device group designed a wearable sleeve to improve pediatric shoulder fracture patient outcomes. The group used ScanIP to create an anatomical model for a patient CT scan, used SolidWorks to prepare their CAD designs, and $3 \mathrm{D}$ printed their prototypes using the CEID 3D printer. The prints were then mailed to the team members. Additionally, the team designed a sensor and demonstrated its feasibility using an Arduino simulator.

On the other hand, the students noted a need for more resources for prototyping. Although the students were provided with increased funding to outsource prototype manufacturing and the CEID offered some prototyping (i.e., 3D printing, machining) and a mailing service, $19 \%$ and $13 \%$ of students were somewhat and extremely unsatisfied with the offered prototyping capacity respectively (Fig. 3). Indeed, many groups were unable to make full use of the resources in the CEID. The maker spaces were not available as they remained closed from March through the end of the semester.

\section{Discussion}

The student surveys and the teaching outcomes provided us with a scope to understand the effective strategies to modify a hands-on design project-based engineering class to remote learning. Overall, we think our adaptation to remote learning was successful. The students were generally satisfied with the online lectures/remote company tours and their project 
a

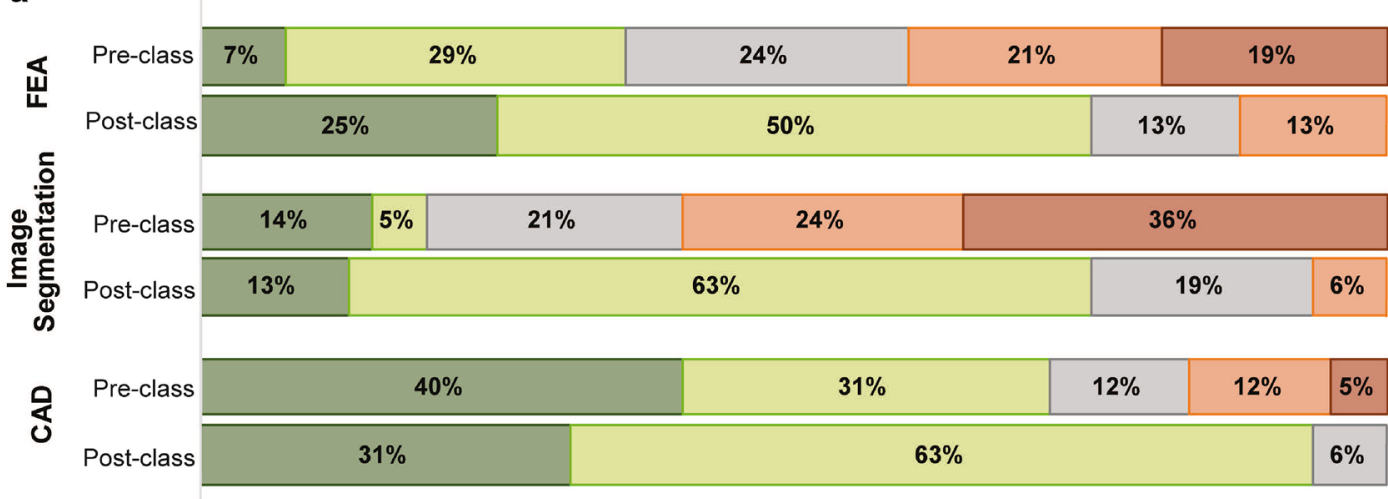

$\square$ Extremely Comfortable $\square$ Somewhat Comfortable $\square$ Neither Comfortable nor Uncomfortable
$\square$ Somewhat Uncomfortable $\square$ Extremely Uncomfortable

b

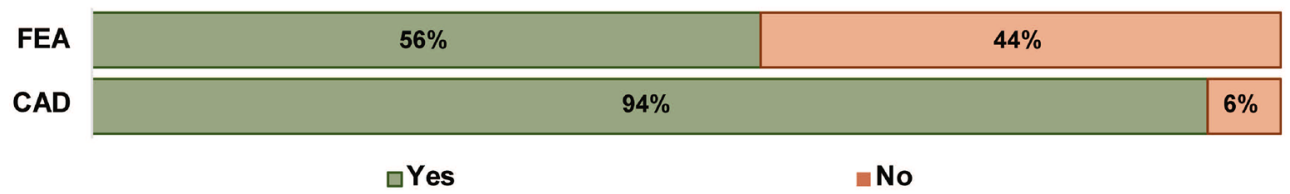

Fig. 2 Software learning outcome. a The students' comfort level with the finite element analysis (FEA), image segmentation and computer-aided design (CAD) software before and after the class. b Students' confidence in using the software in their future career in the post-class survey

Table 1 The projects offered in the Medical Device Design Challenge

\begin{tabular}{|c|c|c|c|c|c|}
\hline & Mentors & Ideation & $\begin{array}{l}\text { Itera- } \\
\text { tive } \\
\text { design }\end{array}$ & $\begin{array}{l}\text { Testing/prototyp- } \\
\text { ing using simula- } \\
\text { tion }\end{array}$ & Physical prototyping \\
\hline Paediatric Proximal Humerus Fracture Device Design & Clinicians & $\checkmark$ & $\checkmark$ & $\begin{array}{l}\text { Arduino } \\
\text { SolidWorks } \\
\text { ScanIP }\end{array}$ & $3 \mathrm{D}$ printing \\
\hline Prostate Cancer Biopsy Device & Clinicians & $\checkmark$ & $\checkmark$ & SolidWorks & Reverse engineering \\
\hline $\begin{array}{l}\text { AI to Improve Hospital Ward Nursing/Patient Com- } \\
\text { munication }\end{array}$ & Clinicians & $\checkmark$ & $\checkmark$ & $--^{\mathrm{a}}$ & - \\
\hline Foot and Ankle Trauma Retractor & Clinicians & $\checkmark$ & $\checkmark$ & $\begin{array}{l}\text { SolidWorks } \\
\text { ABAQUS }\end{array}$ & Consultation with machinist \\
\hline $\begin{array}{l}\text { Improve Stability of Platform for Greater Trochanter } \\
\text { Navigation Platform }\end{array}$ & Industrial Partner & $\checkmark$ & $\checkmark$ & $\begin{array}{l}\text { SolidWorks } \\
\text { ScanIP } \\
\text { ABAQUS }\end{array}$ & $\begin{array}{l}\text { 3D printing, } \\
\text { Consultation with machinist }\end{array}$ \\
\hline
\end{tabular}

${ }^{a}$ The project does not require simulations and physical prototyping

experience. In addition, the class maintained a productive teaching outcome as the projects were finished with high engagement and quality.

The course also reached its mission of providing students with practical experience of using and learning engineering software. Software simulation was especially emphasized in the remote medical device design project as the teams were encouraged to use image processing, CAD tools and FEA software as an alternative to building and testing their prototypes. The distance learning encouraged the students to improve their simulation skills, which plays a critical role in the modern engineering design process. In order to promote simulation software usage in the projects, the availability of simulation tools needs to be increased by providing remote access to the software and sufficient computing power to solve complex FEA models. We had to provide students remote access to our Orthopaedic Department's high-performance computer to solve their FEA models.

Our experience demonstrated that it is possible to conduct project-based engineering classes in a remote form, 


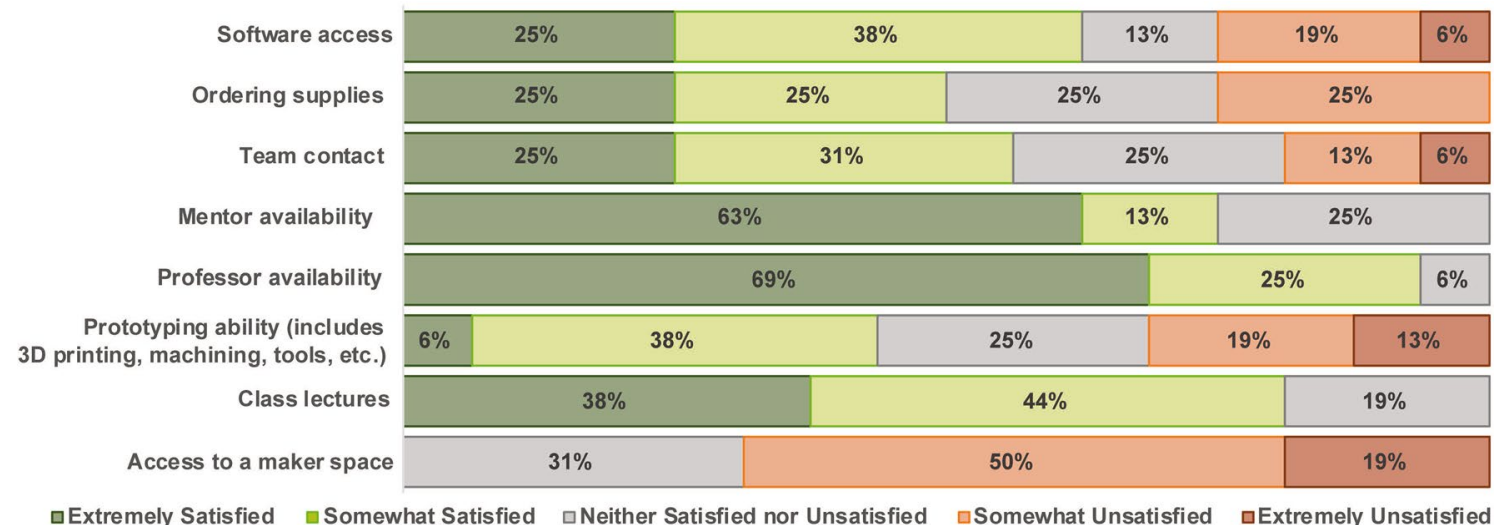

Fig. 3 Survey about remote learning experience after the class

given sufficient support from the faculty team and the support staff. We observed that regular meetings between the mentors, professors and the groups were beneficial for guiding and tracking the projects' progress. Thus, we concluded that increased faculty (professors, design fellows, machinists, etc.) guidance and support, and meeting regularly with each team, are essential to ensure a positive online learning experience.

Teamwork is another vital element in succeeding in a group project. Despite the lack of a physical maker space to foster collaboration and creativity, teamwork was preserved through the form of online meetings. The team members were able to engage their groups, brainstorm and come up with innovative solutions.

Additional funding is necessary to accommodate the increased logistical expenses. Initially, $\$ 500$ was allocated to each group and the faculty decided to increase the team budget to $\$ 1,000$ to facilitate prototyping and mailing materials between team members. Although the five teams only spent less than half of their budgets $(\$ 2,140$ in total), the budget increase was essential to the groups that advanced in the prototyping and testing stage. In addition, two of the teams received $\$ 1,000$ innovation grants from Tsai City, a Yale Innovation Center. In our case, the software licenses were floating licences that allowed for off-campus usage through our VPN. Otherwise, the additional expense in software purchase would be required.

Despite the overall success, we also identified several aspects that could be improved. We realized that the problems of internet connectivity, time zone differences and poor access to a quiet learning space were experienced by a significant proportion of the students in the class. Education equity $[8,9]$ has to be addressed in the era of remote learning with an emphasis on different levels. The lectures should be recorded and made available online. When faced with difficult situations (i.e., challenging home study environments), the students should have accessible and non-stigmatizing ways to reach out for help. With the continuous spread of COVID-19, many universities will employ the hybrid learning in the 2020 Fall semester. [10, 11] Individual students could be granted the priority of returning to campus to learn if they are experiencing difficulties studying in their home environment.

We observed that the format of the lectures and virtual tours needed to be adjusted to allow for more student/lecturer interaction, perhaps through expanding Q\&A sections. These sections should be held at a schedule that accommodates time zone differences, if possible. Likewise, the students felt they did not have enough opportunities to network with industrial and professional leaders because they missed the ability to approach guest lecturers after class and talk to them in person. Improved interaction may be possible with breakout rooms and adding additional "networking" sessions for smaller groups.

Last but not least, many groups were unable to make full use of the resources in the CEID. More communications with the design fellows and machinists at the early stage of the projects could have facilitated these teams. More consultation sessions could be organized, such that the design fellows and machinists can provide advice on prototyping plans and prepare materials for on-campus prototyping in the CEID.

Here we summarize our experience and advice the following Table 2:

Our experience showed that, although challenging, it is feasible to conduct an engineering design class through remote learning. More specifically, with regular guidance and supervision from the teaching faculties and project mentors, the students actively engaged and completed group design projects. Under remote learning, maker space and lab access are limited. Shifting the design projects towards a simulation-oriented approach can alleviate these restrictions. We further concluded that sufficient resources, including access to computational power, software packages, 3D 
Table 2 Summary of our experience and advice to adapt an engineering design course to remote learning

Education equity needs to be highlighted in remote learning. Make certain to have a non-stigmatizing method for students to reach out for help To improve student interactions with the lecturers, create smaller discussion sessions, such as through the use of the breakout room feature

Increased faculty (professors, design fellows, machinists, etc.) guidance and support, including meeting regularly with each team, are essential to ensure that teams are not "stuck" and that teams are on the path to a solution

Increase the availability of simulation tools by providing remote access to software packages and sufficient computing power to solve complex FEA models. Encourage students to build and test prototypes via CAD tools and FEA software

It is possible to realize a certain level of remote prototyping in the campus maker space, with the support from on-campus design fellows and machinists

Larger project budgets are required given the obstacles caused by the remote learning condition (i.e., mailing, prototyping etc.)

printing and machining service, and additional project funds, would help the students succeed. Drawing from the survey responses, we also identified the challenges of studentpresenter interactions and education equity, universal to all remote learning classes. We think the lectures should be particularly aware of them and address them accordingly.

Acknowledgements The authors would like to thank Dean Vincent Wilczynski and Joseph Zinter for their support of the class. We would like to extend our thanks to the CEID design fellows Antonio Medina, Ashlyn Oakes, machinist Nicholas Bernardo and Engineering design advisor Glenn Weston-Murphy for providing prototyping consultations, 3D printing/machining and mailing services. Special thanks to Dr. Kenneth Milligan for offering ScanIP and ABAQUS workshops.

\section{Compliance with ethical standards}

Conflict of interest There is no conflict of interest to disclose.

\section{References}

1. Burgess S, Sievertsen HH (2020) Schools, skills, and learning: The impact of COVID-19 on education. VoxEu org 1

2 Sahu P (2020) Closure of universities due to Coronavirus Disease 2019 (COVID-19): impact on education and mental health of students and academic staff. Cureus 12(4):e7541
3. Wilczynski V (2015) Academic maker spaces and engineering design. In: American Society for Engineering Education

4. Wilczynski V, Iii J, Wilen L (2016) Teaching engineering design in an academic makerspace: Blending theory and practice to solve client-based problems. In: Proceedings of the ASEE Annual Conference \& Exposition, New Orleans, LA, pp 26-29

5. Burns KE, Duffett M, Kho ME, Meade MO, Adhikari NK, Sinuff T, Cook DJ (2008) A guide for the design and conduct of selfadministered surveys of clinicians. Cmaj 179(3):245-252

6 Karlberg M, Löfstrand M, Sandberg S, Lundin M (2013) State of the art in simulation-driven design. Int J Product Dev 18(1):68-87

7 Koziel S, Leifsson L (2016) Simulation-driven design by knowledge-based response correction techniques. Springer, New York

8. Puckett C (2020) COVID-19, technology, and implications for educational equity. Footnotes 48(3)

9. Fain P (2020) Higher education and work amid crisis. Accessed 17 Aug 2020

10. Bentley K (2020) Hybrid learning goes mainstream amid response to COVID-19. https://www.govtech.com/. Accessed 11 Aug 2020

11. Byrnes H (2020) Reopening schools amid COVID-19: A mix of in-person attendance, remote learning and hybrid plans. USA Today. Accessed 17 Aug 2020

Publisher's Note Springer Nature remains neutral with regard to jurisdictional claims in published maps and institutional affiliations. 